\title{
Use of codeine and NSAID combination in rhinogenic headache
}

\author{
Cemal Cingi ${ }^{1}$, Erdem Atalay Cetinkaya ${ }^{2}$, Osman Halid Cam ${ }^{3}$, Fatih Oghan ${ }^{4}$, Nuray Bayar Muluk \\ ${ }^{1}$ Osmangazi University, Faculty of Medicine, Department of Otolaryngology, Eskisehir, Turkey \\ ${ }^{2}$ University of Health Sciences, Antalya Training and Research Hospital, Department of Otorhinolaryngology \\ and Head \& Neck Surgery, Antalya, Turkey \\ ${ }^{3}$ Medeniyet University, Goztepe Training and Research Hospital, Department of Otolaryngology, Istanbul, Turkey \\ ${ }^{4}$ Dumlupinar University, Faculty of Medicine, Department of Otolaryngology, Kutahya, Turkey \\ ${ }^{5}$ Kırıkkale University, Faculty of Medicine, Department of Otolaryngology, Kırıkkale, Turkey
}

\begin{abstract}
Headache is a common complaint which otolaryngologists frequently have to evaluate and treat in practice. Migraine, tension, cluster and sinus-rooted headaches are the most confronted ones in primary visits. Therefore, considerations of multidiscipline may be required to diagnose the rhinogenic and non-rhinogenic headaches. Rhinogenic headache is a distinct type of headache that has attracted an increased amount of attention in the recent years. The mechanism of headache is not yet known. In fact, the treatments of the above-mentioned headaches are different, but they may intersect in some cases. Non-steroid anti-inflammatory drugs (NSAID) and opioids are often used in headache treatment. Codeine, a well-known opioid derivative, has been prescribed for analgesia for a long time. This review aims to discuss the possible use and efficiency of NSAID and codeine combinations in the treatment of rhinogenic headaches.
\end{abstract}

KEYWORDS: sinonasal headache, opioid, codeine, treatment.

\section{INTRODUCTION}

Headache is the chief complaint in daily neurology outpatients' clinics ${ }^{1}$. Although the classification is well studied, there is lack of knowledge about the epidemiology of headache subtypes. In order to make an accurate diagnosis for rhinogenic headache, tension type headache (TTH) and migraine should be well understood. Tension type headache is the most common type of headache. Migraine, cluster headache and rhinogenic or sinus headache are the rest other common causes of headache. Since there are not strict diagnostic criteria between these diseases, many patients are misdiagnosed, leading to mistreatments and social bur$\operatorname{den}^{2-5}$. Not only headache but also accompanying symptoms cause the patient to suffer more. Thus, instead of using the term "headache", we think "headache disorder" is more suitable in for this condition.

Although there has been much progress in the management and the treatment of neurogenic headaches, about half of these patients are not certainly diagnosed. Thirty million patients suffer from headache in the United States, annually. Women compose $75 \%$ of the migraine patients. Migraine rarely happens for any period of time more than two or three times a week and generally reacts to ergotamine, dihydroergotamine, sumatriptan or phenothiazine. It may be necessary to add codeine or oxycodone for the occasional intractable assault. When there are demands for opioids in a migraine patient in quantities higher than 10 to 15 tablets per 


\section{Table 1 Classification of pain types ${ }^{6}$}

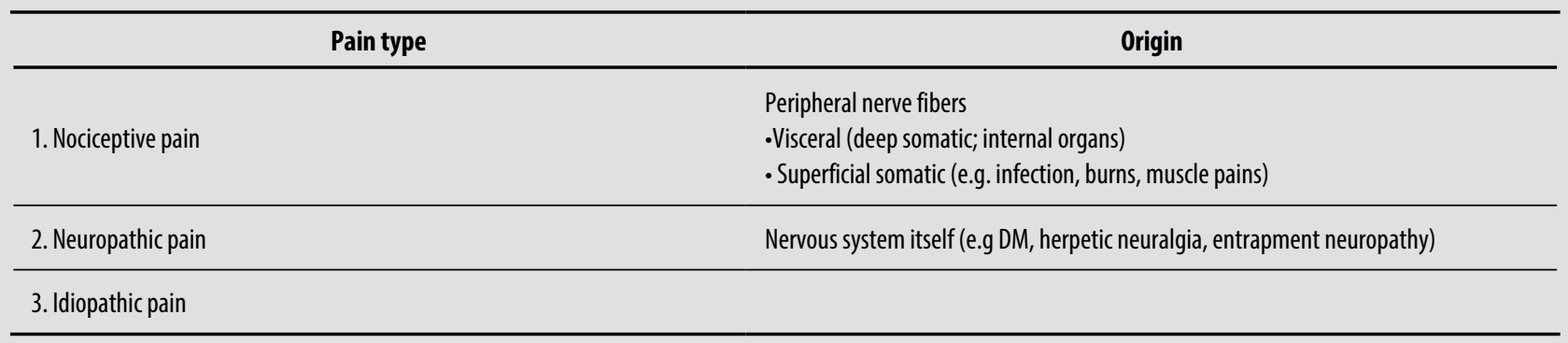

month, there is apparent cause for worry. Therefore, it is unplanned. However, the drug has potential for abuse, and there is still uncertainty about the boundaries to be put on its use. Recently, Markley suggested a limitation of no more than two bottles per month (30 treatments). The main issue is the population with frequent tensiontype headaches. These patients use drugs in large amounts, often in combination ${ }^{6}$. Some claimed theories have been stated for the explanation of patho-physiological changes in migraine. Rebound vasodilatation due do vasoconstriction has been popular for many years. Lately, an extension to this theory has been suggested - intracranial neurovascular changes somehow decrease cerebral perfusion. Migraine may be experienced with or without aura, known as visual, sensory or motor symptoms. Visual aura - photophobia, scotomas and visual lining (especially zigzag lines) - is the most common type of aura; however, migraine without aura accounts for $80 \%$ of the migraine patients. In addition, a typical migraine episode consists of unilateral headache with visual manifestations ${ }^{7-11}$.

Although TTH is the most common type of neurogenic headache, the certain diagnosis of TTH is the most difficult due to the differential diagnosis. The presence of other headache pathologies should be ruled out in order to state the TTH diagnose which means just pain in the head. Since the exact pathogenic process for TTH is unknown, muscular or mental tensions are blamed. Muscles of the scalp and the neck are the responsible muscles, and the stressful events are the responsible mental triggers. Also, there have been some reports showing low cortisone levels in TTH patients, which blame chronic stress and hippocampus atrophy. A usual episodic TTH is self-limited, with moderate pain and usually good responsive to overthe-counter (OTC) drugs. This is why migraine covers most part of the headache studies, pharmacological investments and daily social headache conversations ${ }^{7-14}$.

\section{PATHOPHYSIOLOGY OF RHINOGENIC HEADACHES}

To understand the pathophysiology of rhinogenic headaches, basic patho-physiology and the categories of pains should be well understood. There are three main classifications of pain $^{6}$ (Table 1 ).

Sinus headache or rhinogenic headache is commonly diagnosed and patients with headache usually address their sinuses as a cause of their headache disorder. Almost $98 \%$ of the patients who self-diagnose themselves with sinus headaches meet the migraine without aura criteria in according to the International Headache Society Guidelines $(\text { IHSG })^{15}$. The diagnostic criteria for sinus or rhinogenic headache are shown in Table 2 according to

\section{Table 2}

\section{Classification of pain types ${ }^{6}$}

\begin{tabular}{cc}
\hline A & Frontal headache accompanied by pain in one or more regions of the face, ears or teeth and fulfilling criteria C and D \\
\hline B & Clinical $^{*}$, nasal endoscopic, CT and/or MRI and/or laboratory evidence of acute or acute-on-chronic rhinosinusitis \\
\hline C & Headache and facial pain develop simultaneously with the onset of acute exacerbation of rhinosinusitis \\
\hline D & Headache and/or facial pain resolve within 7 days after remission or successful treatment of acute or acute-on-chronic rhinosinusitis \\
\hline *Clinical evidence: Purulence in the nasal cavity and/or discharge, nasal obstruction, hyposmia and/or anosmia, fever \\
\hline
\end{tabular}


IHSG $2005^{16}$. Some rhinologic and anatomic disorders (deviation of nasal septum, inferior turbinate hypertrophy, pneumatised turbinate, mucosal contact points and sinus mucosal atrophy) are thought to induce rhinogenic headache; however, there is not any evidence to support these theories ${ }^{17-19}$.

Additionally, inflammation in exudates due to allergens and infections leads to blockage or decrease in sinus drainage, which causes trigeminal nerve fibres stimulations. On the other hand, these pathologies pretend to be a trigger that starts the trigemino-vascular reflex resulting with the release of substance $\mathrm{P}(\mathrm{SP})$ in the sinonasal mucosa. This reflex is an axonal reflex which causes plasma exudation due to the vasodilatation ${ }^{20}$. This process is known as neurogenic oedema and the pain caused by SP is transmitted to the cortex by afferent $\mathrm{C}$ fibres. The inflammation process due to extrinsic factors and neurogenic oedema starts the synthesis of prostanoids, whose role in the local sensation of pain is very well known. These reflexes and local processes are blamed to be the triggers of migraine headaches $^{17,21}$. The trigeminal nerve branches innervating the meningeal blood vessels release substance $\mathrm{P}$ and calcitonin gene-related peptide (CGRP) ${ }^{22,23}$.

The trigeminal nerve has three main divisions with common synapses at the level of the trigeminal caudal nucleus: N. Ophtalmicus, N. Maxillaries and N. Mandibularis. These sensory fibres transmit stimuli from the face, the sinuses, the nasal mucosa, dental sensations, and the anterior middle and posterior meninges in the cranial fossa ${ }^{24}$. This can be an evidence for why the majority of rhinogenic/sinus-originated headache disorders criteria meet the TTH or migraine headache disorders criteria and explain the complex relationship.

\section{TREATMENT}

\section{Effects of Non-Steroid Anti-inflammatory Drugs (NSAIDs) in Headache Disorders}

As we told above, the inflammation process stimulates the arachidonic acid metabolism which leads to the synthesis of prostanoids. The activation of phospholipase $\mathrm{A}_{2}$ induces the release of arachidonic acid from the cell membrane. Arachidonic acid follows three main enzymatic pathways catalyzed by cyclooxygenase I (COX I), cyclooxygenase II (COX II) and lipoxygenase to form prostaglandin (PG) I family, prostaglandin II family and leukotrienes. The products from the cyclooxygenase II are mainly responsible for fever, pain and inflammation ${ }^{25}$. PG sensitizes the nerve endings in the local inflammation area ${ }^{26}$. Additionally, transmission of pain impulses through the spinal cord is thought to be facilitated by prostaglandins ${ }^{27}$. The NSAIDs are COX enzyme inhibitors (both COX I and COX II); they block the prostaglandin synthesis and cause a shift in the enzymatic pathway. As a result, inflammation in the local area and the pain excitability of spinal nerves are reduced and the sense of pain is relieved ${ }^{28}$.

\section{Effects of Opioids in Headache Disorders}

The effects of opioids are based on the agonism in opioid receptors. There are two opioid receptors: mu and kappa. Delta and sigma receptors have unknown significance. The penetration of an opioid molecule with an agonist results in analgesia, respiratory depression and sedation. As adverse effects, the mu receptors are responsible for euphoria and constipation, while dysphoria is related with kappa receptor agonism and respiratory depression for both. The effects of mu receptors are unlimited and directly proportional to opioid doses, which results in two major undesired effects due to the mu receptor agonism: respiratory depression and dependence. Kappa receptors are more likely to be considered as safe, since the response to these receptors is limited and does not increase with high doses, which also means less analgesia in comparison to mu receptors ${ }^{25}$. Tolerance is commonly known in response to the use of opioids, resulting in greater doses of drug required in order to maintain the same effect that was formerly supplied with smaller doses ${ }^{29,30}$.

Codeine is an opioid derivative and acts as a prodrug. Ten percent of codeine is transformed to morphine by cytochrome $\mathrm{P} 450$ in the human body. Morphine is the active metabolite of codeine and has agonism on both mu and kappa receptors. The analgesic action of morphine depends on the affinity to the receptors in spinal cord and also to the receptors in higher levels of the central nervous system. Morphine does not have any effect on peripheral nerve conductivity or the thresholds of afferent nerve fibres. When morphine binds to its receptor, intracellular adenylate-cyclase is inhibited, leading to cyclic adenosine monophosphate (cAMP) decrease. As a consequence to this decrease, the release of substance $\mathrm{P}$, dopamine, acetylcholine, which are known as neurotransmitters, is blocked and the sense of pain is reduced ${ }^{31}$. Overuse of codeine by headache-prone patients often results in drug-induced rebound headache followed by symptomatic drug dependence, tolerance (refractory to prophylactic drugs), and symptoms of withdrawal. Overuse of codeine products in this situation was described as taking 3 or more doses per day more frequently than 2 days a week. Usage frequency may be higher than the dose. Rebound headache fea- 
tures include morning headache, end-of-dose headache, or headache enhancement when overused medication is discontinued. Stopping the symptomatic medication can lead to a period of headache and headache enhancement afterwards. Analgesic overuse can transform episodic migraine or episodic tension headache into daily headache and can perpetuate the syndrome ${ }^{31,32 .}$

Opioids are also commonly used to treat tension-type headache. In preparations coupled with aspirin or acetaminophen, codeine, propoxyphene and oxycodone are generally prescribed. Codeine combinations with aspirin or acetaminophen and butalbital are also commonly used ${ }^{32}$. Codeine and propoxyphene are certainly more powerful analgesics than aspirin and acetaminophen, but few if any controlled studies have been conducted to determine the comparative efficacy of the combination of these compounds with and without an opioid drug in patients with tension headache. Such studies would be of excellent significance given the frequent use of these medicines. Codeine and its combination with paracetamol is one of the mainly prescribed drugs in the management of headache, although there is no evidence for its effectiveness in headache disorders ${ }^{6}$. Even if codeine combinations with aspirin increase the analgesic effect, it is not thought to have any clinical benefits ${ }^{33}$.

It is important that the analgesia provided by single-entity agents confirms repeatedly published clinical studies over the past 3 decades. For the musculoskeletal pain, NSAIDs are more effective than conventional opioid doses. In reality, $5 \mathrm{mg}$ of oxycodone (the most frequently prescribed dose coupled with acetaminophen) is no more efficient than placebo. Note, however, that a tiny increase in ibuprofen-added opioid (oxycodone $5 \mathrm{mg}$ ) increases pain relief. This shows the fact that opioids are synergistic, and by titrating extra opioid increments to an optimally dosed nonopioid, analgesia can be enhanced. In contrast with that, Becker ${ }^{25}$ emphasized that "in many cases, it is better to write separate prescriptions for the opioid and the nonopioid at dosages that more precisely address the analgesic needs of the patient", especially for dental pain. On the other hand, there is no information about using codeine with any other NSAIDs in sinonasal headache.

\section{CONCLUSIONS}

The sense, transmission, intensity and the duration of headache are based on complex mechanisms. The use of codeine combination with an
NSAID drug may be more useful in controlling rhinogenic headache and head and neck pain by transecting both known transmissions of pain in local and central levels.

Conflict of interest: The authors declare that there is no conflict of interest.

Acknowledgement: Preparation of this paper including designing and planning was supported by Continuous Education and Scientific Research Association.

Acknowledgment of Financial Support/Funding: None.

Contribution of authors: All authors have equally contributed to this work.

\section{REFERENCES}

1. Taylor FR. Diagnosis and classification of headache. Prim Care. 2004;31(2):243-59, v.

2. Lipton RB, Stewart WF, Diamond S, Diamond ML, Reed M. Prevalence and burden of migraine in the United States: data from the American Migraine Study II. Headache. 2001;41(7):646-57.

3. Foroughipour M, Sharifian SM, Shoeibi A, Ebdali Barabad N, Bakhshaee M. Causes of headache in patients with a primary diagnosis of sinus headache. Eur Arch Otorhinolaryngol. 2011;268(11):1593-6. DOI: 10.1007/ s00405-011-1643-6. Epub 2011 May 31.

4. Herzallah IR, Hamed MA, Salem SM, Suurna MV. Mucosal contact points and paranasal sinus pneumatization: Does radiology predict headache causality? Laryngoscope. 2015;125(9):2021-6. DOI: 10.1002/lary.25194. Epub 2015 Feb 25.

5. Kim SH. A case of nasal septal deviation-induced rhinogenic contact point otalgia. Am J Otolaryngol. 2015;36(3):451-5. DOI: 10.1016/j.amjoto.2015.01.008. Epub 2015 Jan 14.

6. Ziegler DK. Opioids in headache treatment. Is There a role? Neurol Clin. 1997;15(1):199-207.

7. Burgos-Vega C, Moy J, Dussor G. Meningeal afferent signaling and the pathophysiology of migraine. Prog Mol Biol Transl Sci. 2015;131:537-64. DOI: 10.1016/bs.pmbts.2015.01.001. Epub 2015 Feb 9.

8. Ambrosini A, D’Alessio C, Magis D, Schoenen J. Targeting pericranial nerve branches to treat migraine: Current approaches and perspectives. Cephalalgia. 2015;35(14):1308-22. DOI: 10.1177/0333102415573511. Epub 2015 Mar 3.

9. Espinosa-Sanchez JM, Lopez-Escamez JA. New insights into pathophysiology of vestibular migraine. Front Neurol. 2015;6:12. DOI: 10.3389/ fneur.2015.00012. eCollection 2015

10. Eren Y, Dirik E, Neșelioğlu S, Erel Ö. Oxidative stress and decreased thiol level in patients with migraine: cross-sectional study. Acta Neurol Belg. 2015;115(4):643-9. DOI: 10.1007/s13760-015-0427-y. Epub 2015 Jan 17.

11. Dussor G. ASICs as therapeutic targets for migraine. Neuropharmacology. 2015;94:64-71. DOI: 10.1016/j.neuropharm.2014.12.015. Epub 2015 Jan 9.

12. Arruda MA, Arruda R, Guidetti V, Bigal ME. Psychosocial adjustment of children with migraine and tension-type headache - a nationwide study. Headache. 2015;55 Suppl 1:39-50. DOI: 10.1111/head.12510. Epub 2015 Feb 6.

13. Domingues RB, Duarte H, Rocha NP, Teixeira AL. Reduced serum levels of adiponectin in tension-type headache. Clin Neurol Neurosurg. 2015;131:82-5. DOI: 10.1016/j.clineuro.2015.01.026. Epub 2015 Feb 7. 
14. Bayraktutan OF, Demir R, Ozel L, Ozdemir G, Ertekin A. Prevalence of tension-type headache in individuals aged between 18-65 years in the Eastern Parts of Turkey. Eurasian J Med. 2014;46(2):78-83. DOI: 10.5152/ eajm.2014.20.

15. Cady RK, Schreiber CP. Sinus headache: a clinical conundrum. Otolaryngol Clin North Am. 2004;37(2):267-88.

16. Silberstein SD, Olesen J, Bousser MG, Diener HC, Dodick D, First M, et al. The International Classification of Headache Disorders, 2nd Edition (ICHD-II) - revision of criteria for 8.2 Medication-overuse headache. Cephalalgia. 2005;25(6):460-5.

17. Cukurova I, Cetinkaya EA, Demirhan E, Avci A. Long-term histological examination of inferior concha after radiofrequency thermal ablation. J Laryngol Otol. 2011;125(2):158-61. DOI: 10.1017/S0022215110001532. Epub 2010 Aug 23.

18. Cady RK, Dodick DW, Levine HL, Schreiber CP, Eross EJ, Setzen M, et al. Sinus headache: a neurology, otolaryngology, allergy, and primary care consensus on diagnosis and treatment. Mayo Clin Proc. 2005;80(7):908-16.

19. Pipolo C, Portaleone S, Felisati G. Nose and headache: what have we learned? Naso e cefalee: cosa abbiamo imparato. Neurol Sci. 2011;32(Suppl1):S131-3. DOI: 10.1007/s10072-011-0531-6.

20. Stammberger H, Wolf G. Headaches and sinus disease: the endoscopic approach. Ann Otol Rhinol Laryngol Suppl. 1988;134:3-23.

21. Cady RK, Schreiber CP. Sinus headache or migraine? considerations in making a differential diagnosis. Neurology. 2002;58(9 Suppl 6):S10-4

22. Moskowitz MA, Cutrer FM. Sumatriptan: a receptor-targeted treatment for migraine. Annu Rev Med. 1993;44:145-54.

23. Goadsby PJ, Edvinsson L, Ekman R. Release of vasoactive peptides in the extracerebral circulation of humans and the cat during activation of the trigeminovascular system. Ann Neurol. 1988;23(2):193-6.

24. Schreiber CP. The pathophysiology of primary headache. Prim Care. 2004;31 (2):261-76, v-vi.
25. Becker DE. Pain Management: Part 1: Managing acute and postoperative dental pain. Anesth Prog. 2010;57(2):67-79. DOI: 10.2344/0003-300657.2.67.

26. Bley KR, Hunter JC, Eglen RM, Smith JA. The role of IP prostanoid receptors in inflammatory pain. Trends Pharmacol Sci. 1998;19(4):141-7.

27. Beiche F, Scheuerer S, Brune K, Geisslinger G, Goppelt-Struebe M. Upregulation of cyclo-oxygenase- 2 mRNA in the rat spinal cord following peripheral inflammation. FEBS Lett. 1996;390(2):165-9.

28. Mitchell JA, Warner TD. Cyclo-oxygenase-2: pharmacology, physiology, biochemistry and relevance to NSAID therapy. Br J Pharmacol. 1999;128(6):1121-32. DOI: 10.1038/sj.bjp.0702897.

29. Martin WR. General problems of drug abuse and drug dependence. In: Martin WR (eds). Drug Addiction I. Handbuch der experimentellen Pharmakologie / Handbook of Experimental Pharmacology (Heffter-Heubner / New Series), vol 45 / 1. Springer, Berlin, Heidelberg; 1977, p.3-40. DOI: https://doi.org/10.1007/978-3-642-66612-4_1.

30. Jasinski DR. Assessment of the abuse potentiality of the morphine like drugs (Methods Used in Man). In: Martin WR (eds). Drug Addiction I. Handbuch der experimentellen Pharmakologie / Handbook of Experimental Pharmacology (Heffter-Heubner / New Series), vol 45 / 1. Springer, Berlin, Heidelberg; 1977, p.197-258. DOI: https://doi. org/10.1007/978-3-642-66612-4_4.

31. Sarne Y, Fields A, Keren O, Gafni M. Stimulatory Effects of opioids on transmitter release and possible cellular mechanisms: overview and original results. Neurochem Res. 1996;21(11):1353-61.

32. Linet MS, Stewart WF, Celentano DD, Ziegler D, Sprecher M. An epidemiologic study of headache among adolescents and young adults. JAMA. 1989;261(15):2211-6.

33. Zhang WY, Po AL. Do codeine and caffeine enhance the analgesic effect of aspirin?-A systematic overview. J Clin Pharm Ther. 1997;22(2):79-97. 